\title{
O tratamento dos PADOs na gestão orçamentária de uma empresa de telecomunicações
}

The processing of $P A D O$ in the budgeting management of a telecommunications company

\section{El tratamiento del PADO en la gestión del presupuesto de una empresa de telecomunicaciones}

\section{Márcia Maria dos Santos Bortolocci Espejo}

Doutora em Controladoria e Contabilidade pela Universidade de São Paulo

Professora do Programa de Pós-Graduação em Ciências Contábeis da Fundação Universidade Federal de Mato Grosso do Sul

Endereço: Av. Sen. Filinto Müler, 1555, Vila Ipiranga

CEP: 79074-460 - Campo Grande/MS - Brasil

E-mail: marcia.bortolocci@ufms.br

Telefone: (67) 3345-7219

\section{Emanuelle Fabiana Said Branco}

Especialista em Controladoria pela Universidade Federal do Paraná

Endereço: Av. Prefeito Lothário Meissner, 632, Jardim Botânico

CEP: 80210-170 - Curitiba/PR - Brasil

E-mail: manusaid@hotmail.com

Telefone: (41) 3360-4417

\section{Henrique Portulhak}

Doutorando em Contabilidade pela Universidade Federal do Paraná

Professor Assistente do Departamento de Contabilidade da Universidade Federal do Paraná Endereço: Av. Prefeito Lothário Meissner, 632, Jardim Botânico

CEP: 80210-170 - Curitiba/PR - Brasil

E-mail: henrique.portulhak@ufpr.br

Telefone: (41) 3360-4417

\section{Patricia Villa Costa Vaz}

Doutoranda em Contabilidade pela Universidade Federal do Paraná

Endereço: Av. Prefeito Lothário Meissner, 632, Jardim Botânico

CEP: 80210-170 - Curitiba/PR - Brasil

E-mail: patriciavilla00@gmail.com

Telefone: (41) 3360-4417

Artigo recebido em 01/05/2016. Revisado por pares em 29/08/2016. Reformulado em 24/03/2017. Recomendado para publicação em 26/05/2017 por Carlos Eduardo Facin Lavarda (Editor-Chefe). Publicado em 31/08/2017. 


\section{Resumo}

A pesquisa teve como objetivo investigar como os Procedimentos para Apuração de Descumprimento de Obrigações (PADOs) são considerados na gestão orçamentária de uma empresa de telecomunicações. Realizou-se um estudo de caso em uma empresa brasileira, na qual foram aplicados questionários para três funcionários envolvidos no processo de planejamento e controle orçamentário dos PADOs, além de análise documental em 132 processos instaurados contra a empresa investigada no período entre 2001 e 2014 . Verificou-se que o controle e planejamento dos PADOs é realizado de forma adequada, proporcional à importância e à severidade das situações. Contudo, percebeu-se que o planejamento orçamentário é prejudicado pela ausência de procedimentos padronizados da agência reguladora que possibilitariam a estimação de parâmetros importantes para a elaboração do orçamento. Os resultados oferecem oportunidades de melhoria na gestão orçamentária da organização estudada, subsidiando reflexões para empresas sujeitas à regulação da ANATEL ou de outras agências reguladoras.

Palavras-chave: Orçamento; Empresas Reguladas; Procedimento para Apuração de Descumprimento de Obrigações (PADO); Telecomunicações

\section{Abstract}

The research aimed to investigate how Procedures for the Determination of Bond Noncompliance (PADO) are considered in the budgeting management of a telecommunications company. A case study was conducted in a Brazilian company, in which questionnaires were applied to three employees involved in the planning process and budgeting control of PADO, and document analysis in 132 cases brought against the company investigated between 2001 and 2014. It was found that control and planning of PADO is done adequately proportional to the importance and severity of situations. However, it was noted that the budget planning is hampered by the lack of standardized procedures of the regulatory agency that would enable the estimation of important parameters for the preparation of the budget. Results offer opportunities for improvement in the budget management of the organization, supporting reflections for companies' subject to regulation by ANATEL or other regulatory agencies.

Keywords: Budget; Regulated Companies; Procedures for the Determination of Bond Noncompliance (PADO); Telecommunications

\section{Resumen}

La investigación tuvo como objetivo investigar cómo se consideran los Procedimientos para la Determinación de Incumplimiento de Obligaciones (PADO) en la gestión del presupuesto de una empresa de telecomunicaciones. Se realizó un estudio de caso en una empresa brasileña, en el que se aplicaron cuestionarios a tres funcionarios que intervienen en el proceso de planificación y control del presupuesto de PADO, y el análisis de documentos en 132 procedimientos presentados contra la empresa investigada entre 2001 y 2014. Se encontró que el control y la planificación de PADO se realiza adecuadamente y de forma proporcional a la importancia y la gravedad de las situaciones. Sin embargo, se observó que la planificación del presupuesto se ve obstaculizada por la falta de procedimientos estandarizados de la agencia reguladora que permita a la estimación de los parámetros importantes para la preparación del presupuesto. Los resultados ofrecen oportunidades de mejora en la gestión del presupuesto de la organización estudiada, y pueden subvencionar reflexiones de las empresas sujetas a regulación por parte de ANATEL u otras agencias reguladoras.

Palabras clave: Presupuesto; Empresas Reguladas; Procedimientos para la Determinación de Incumplimiento de Obligaciones (PADO); Telecomunicaciones 


\section{Introdução}

Com o avanço tecnológico, o setor de telecomunicações no Brasil cresceu significativamente na última década, principalmente com a privatização da prestação de serviços que modernizou a infraestrutura gerando uma disputa acirrada pela conquista de novos clientes e a fidelização dos mesmos. Em decorrência da concorrência, o mercado se tornou cada vez mais exigente e, em consequência, as empresas de telecomunicações procuram desde então oferecer produtos que atendam as necessidades e expectativas dos clientes. Entretanto, os esforços e investimentos não são suficientes para atender a demanda com a qualidade exigida pelos órgãos reguladores, gerando insatisfação dos clientes e fazendo com que o setor de telecomunicações domine o ranking de reclamações nos órgãos de proteção e defesa do consumidor.

A Agência Nacional de Telecomunicações (ANATEL) é o órgão responsável por regulamentar e fiscalizar os serviços prestados pelas operadoras de telefonia. Em caso de descumprimento das obrigações legais por parte das empresas de telecomunicação, a ANATEL possui a função de aplicar multas que por sua vez são precedidas de processos administrativos, denominados como Procedimento para Apuração de Descumprimento de Obrigações (PADO).

O Tribunal de Contas da União (TCU) apresentou em seu Relatório e Parecer Prévio sobre as contas do Governo da República - exercício 2013 - um levantamento realizado em 17 instituições públicas no período de 2009 a 2013 que analisou a arrecadação de multas aplicadas por órgãos e entidades federais de regulação e fiscalização. Das 17 instituições analisadas pelo TCU, a ANATEL foi a sexta que mais aplicou multas no período de 2009 a 2013 e a terceira no ranking com o maior montante aplicado. Segundo o levantamento, a ANATEL aplicou 20,9 mil multas, o equivalente a $\mathrm{R} \$ 6,9$ bilhões contra operadoras de telecomunicações por descumprimento de obrigações. As multas aplicadas, dessa forma, possuem montante significativo, pois representam aproximadamente $6 \%$ do total investido pelas operadoras no período (TELECO, 2016).

Outro fator que chama a atenção neste levantamento é a discrepância entre o montante de multas aplicadas em relação aos valores efetivamente pagos aos órgãos regulamentadores. Em média, as instituições arrecadaram apenas 5,8\% das multas aplicadas, sendo que a ANATEL ficou abaixo dessa média, apresentando o terceiro pior resultado, com $4,3 \%$ de arrecadação das multas do período (TELECO, 2016). Para que as empresas de telecomunicações acompanhem e administrem de forma adequada o grande volume de processos administrativos apresentados e as consequentes multas aplicadas pela ANATEL, fazse necessário um instrumento de planejamento e controle orçamentário eficiente e eficaz, que possa estabelecer com antecedência as ações a serem executadas e os recursos que deverão ser desembolsados, já que a ausência de cumprimentos desses procedimentos pode aumentar o valor de atuais e futuras multas, comprometendo os resultados da empresa e até mesmo a continuidade de suas operações.

Considerando esta estrutura atual do setor de telecomunicações, verifica-se também que as empresas componentes deste ramo precisam de intensos investimentos em pesquisa e desenvolvimento (P\&D), uma vez que a inovação tecnológica constante é seu grande diferencial (GALINA; PLONSKI, 2005). Portanto, tal necessidade de inovação inerente ao ramo faz com que o setor dependa de algumas empresas dominantes, principalmente companhias transnacionais, que acabam assumindo o controle do mercado, por meio de processos de fusão com empresas menores. Assim, as empresas menores que resistem aos processos de combinação de negócios e que não conseguem investimentos adequados em $\mathrm{P} \& \mathrm{D}$, tornam-se dependentes de incentivos legais e outros investimentos do governo, bem como de acordos com universidades e instituições de pesquisa que cooperam com tais empresas no 
fornecimento de tecnologia (GALINA; PLONSKI, 2005). Em conjunto, estes componentes legais e as características inerentes do setor impactam na estrutura e na gestão orçamentária das empresas do ramo.

À luz dessas considerações, a questão de pesquisa que orienta a presente investigação é a seguinte: como os PADOs são tratados na gestão orçamentária de uma empresa de telecomunicações? Sendo assim, a presente pesquisa tem o intuito de investigar como os PADOs são considerados na gestão orçamentária de uma empresa desse ramo, visando a melhoria da tomada de decisão em termos de planejamento.

Em específico, a investigação busca (i) identificar o tempo médio de julgamento, vencimento e pagamento dos PADOs, (ii) verificar as premissas empregadas pela empresa para classificar os PADOs quanto ao risco de perda, (iii) averiguar os critérios utilizados pela empresa para provisionar os PADOs, (iv) investigar o posicionamento da empresa na decisão do pagamento do PADO, (v) verificar como a empresa trata o orçamento dos PADOs, e (vi) levantar possíveis pontos de melhoria na gestão orçamentária desses procedimentos.

Além da representatividade e dos montantes envolvidos nas autuações realizadas pela ANATEL junto às empresas de telecomunicações, conforme já mencionado, a presente investigação se justifica ao oportunizar reflexões sobre os desafios e as oportunidades de desenvolvimento e maturidade da gestão orçamentária dos PADOs nessas empresas, podendo oferecer subsídios para uma melhor utilização dessa ferramenta nessas organizações.

Sob um aspecto social, investigações dessa natureza, que subsidiem uma melhor gestão dos PADOs e das multas decorrentes desses processos, podem resultar em menor custo dos serviços oferecidos aos consumidores em função do aumento na eficiência desses atendimentos. Já pelo ponto de vista teórico, pesquisas com este direcionamento podem oferecer novos conhecimentos à academia a respeito do tratamento de aspectos específicos que façam parte da gestão orçamentária e do controle gerencial de organizações do setor de telecomunicações e demais setores regulados, visto que pesquisas que envolvam tais elementos podem ser consideradas escassas.

Além da contextualização, da problematização e das justificativas da pesquisa apresentadas nessa seção, o presente artigo se estrutura da seguinte forma: a segunda seção contempla o referencial teórico-empírico utilizado para a investigação, que envolve tópicos sobre planejamento e controle orçamentário e sobre os PADOs; a terceira seção apresenta a metodologia adotada para a pesquisa; em seguida, é apresentada a análise dos dados e, por fim, as principais conclusões extraídas do estudo.

\section{Referencial Teórico}

O processo de gestão de uma organização envolve diversas funções, dentre as quais o planejamento e o controle. Nesse processo, enquanto o planejamento é o momento para que as metas da organização sejam determinadas, o controle busca assegurar que os planos determinados sejam devidamente cumpridos (GUERREIRO, 1992). Dentre as principais ferramentas existentes que viabilizam o acompanhamento do processo de gestão por meio de indicadores financeiros encontra-se o orçamento (OYADOMARI et al., 2008).

De acordo com Frezatti (2009), o orçamento empresarial pode ser entendido como um plano financeiro que visa a implantação da estratégia escolhida pela organização para um determinado período. De acordo com o autor, o orçamento atua em um papel de planejamento por contemplar e refletir as prioridades e o direcionamento que a entidade deseja tomar em determinado período, bem como atua como uma ferramenta de controle ao possibilitar uma avaliação de desempenho da entidade, de suas áreas e de seus gestores de acordo com a estratégia escolhida pela organização. 
Para Lunkes (2007), o orçamento é uma ferramenta de planejamento, que possibilita guiar e organizar os gastos, e também uma ferramenta de controle, que possibilita contingenciar e controlar os gastos. De acordo com Horngren, Sundem e Stratton (2004), ao ser capaz de ligar o planejamento e o controle de gestão, o orçamento conduz os gestores a refletirem sobre a estratégia adotada pela organização e sobre o planejamento de próximos períodos.

Ainda, podem ser detalhadas outras funções que podem ser exercidas por meio do orçamento, como ao apoiar o planejamento e coordenação das atividades da organização, auxiliar na decisão de alocação de recursos, prover meios para motivar um melhor desempenho dos funcionários e garantir a conformidade das atividades empresariais com as normas sociais (COVALESKI et al., 2007).

Vale ressaltar que a adoção do orçamento é capaz de evitar o surgimento de potenciais restrições financeiras e operacionais (HORNGREN; SUNDEM; STRATTON, 2004) e, para isso, é importante uma leitura adequada do ambiente externo, com o objetivo de possibilitar a identificação de oportunidades competitivas e de minimizar impactos de possíveis problemas (SCHNORRENBERGER ET AL., 2013). Em consequência, certas variáveis organizacionais, como a incerteza, podem motivar adaptações na gestão orçamentária de determinadas organizações (COVALESKI et al., 2007).

Entretanto, são estas variáveis organizacionais que também podem ensejar críticas ao processo de elaboração e acompanhamento do orçamento. Um destes fatores é a possibilidade de criação de folga orçamentária, a depender da inclinação do gerente e dos elaboradores do orçamento (HARTMANN; MAAS, 2010). Segundo estes autores, a possibilidade de criação de folga pode gerar alguns comportamentos antiéticos, tornando-se uma das causas de falhas no processo orçamentário das organizações.

Além desse aspecto comportamental dos responsáveis pela elaboração do orçamento, outras críticas ao seu processo envolvem a participação dos demais colaboradores da organização em seu processo. Isto porque, muitas vezes, o processo orçamentário pode acabar fortalecendo o comando e controle vertical, deixando em segundo plano a comunicação e participação dos gestores (FREZATTI et al., 2010). Portanto, uma excessiva preocupação com redução de custos, ao invés do foco na criação de valor, acaba tornando o orçamento vazio de significado, pois não representará a realidade da organização.

Ademais, Fank, Angonese e Lavarda (2011) relatam que uma preocupação excessiva com informações passadas, em detrimento de buscas de perspectiva futura, acaba por prejudicar, também, o processo orçamentário. Sendo assim, o orçamento pode não demonstrar a realidade da empresa, ao desconsiderar o ambiente competitivo e o cenário econômico no qual a empresa se encontra.

Desta forma, é importante reconhecer que não há um modelo de orçamento ideal (HANSEN; OTLEY; VAN DER STEDE, 2003), apesar da existência de diversos modelos, como o orçamento empresarial, o orçamento base-zero (LUNKES, 2003), o orçamento baseado em atividades e o beyond budgeting (HANSEN; OTLEY; VAN DER STEDE, 2003). A utilização de ferramentas de controle gerencial, como o orçamento, deve passar pela consideração de elementos específicos da organização na qual ele será utilizado, demandando a realização de adaptações de acordo com suas necessidades (LUNKES, 2003; ZIMMERMAN, 2011).

Portanto, considerando estas características do processo orçamentário, entende-se que no contexto analisado nesta pesquisa a existência do PADO gera custos de transação, tornandose um risco regulatório inerente à atividade que deve ser incorporado ao orçamento. A noção dos custos de transação advém de Coase (1937), ao indicar que estes são os custos de negociar, redigir e garantir o cumprimento de um contrato (unidade básica). A teoria dos custos de transação nega a simetria de informações, onde tanto o comprador como o vendedor conhecem 
todas as características relevantes do objeto de troca. Seus fatores determinantes são: racionalidade limitada, complexidade e incerteza (geram, em conjunto, uma assimetria de informação, diferenças nas informações que as partes envolvidas possuem), oportunismo (associado à manipulação de assimetrias de informação) e especificidade de ativos (associada ao pequeno número de agentes que participam das transações, reduzindo os produtores capazes de ofertá-los e os demandantes interessados em adquiri-los), que geram dificuldades no momento de negociar e redigir um contrato e garantir sua execução (KUPFER; HASENCLEVER, 2002).

Sendo assim, o pressuposto básico da Economia dos Custos de Transação (ECT) é de que existem custos na utilização do sistema de preços bem como na condução de contratos intra-firma. Portanto, para o funcionamento do sistema econômico, não apenas os contratos efetuados via mercados são importantes, mas também aqueles coordenados centralmente pelas firmas. O segundo pressuposto, herdado do institucionalismo tradicional, é de que as transações ocorrem em um ambiente institucional estruturado e que as instituições não são neutras, ou seja, interferem nos custos de transação. $\mathrm{O}$ ambiente institucional corresponde ao sistema de normas (restrições informais, regras formais e sistemas de controle) que afetam o processo de transferência dos direitos de propriedade, exigindo recursos reais para operarem (ZYLBERSTAJN, 1995, p. 16).

Quanto aos riscos regulatórios inerentes à atividade de prestação de serviços de telecomunicação, Camacho, Bragança e Rocha (2005, p. 106) indicam que "o risco regulatório é um exemplo típico de risco assimétrico. Isso porque, consensualmente, o retorno positivo potencial gerado pela regulação é normalmente menor que o retorno negativo potencial para a empresa regulada". Portanto, "a regulação desempenha função primordial, ao buscar reproduzir as condições de competição, para que os consumidores tenham acesso a produtos e serviços com a qualidade e os níveis de preços que obteriam em um ambiente competitivo" (SALGADO, 2003, p. 03).

Conforme Kubota (2005, p. 10-11), os riscos regulatórios inerentes à agência reguladora das telecomunicações são compostos por cinco elementos:

\footnotetext{
- As instituições legislativas e executivas: os mecanismos formais para indicar legisladores e tomadores de decisão, para elaborar e implementar leis e regulações e para determinar as relações entre as duas instituições.

- As instituições jurídicas: os mecanismos formais de indicar juízes e determinar a estrutura interna do Judiciário e resolver, imparcialmente, disputas entre partes privadas ou entre partes privadas e o Estado. (...)

- As capacidades administrativas.

- Normas informais e particulares: que são amplamente aceitas e que tacitamente restringem as ações de indivíduos ou instituições.

- A característica dos interesses sociais: os interesses sociais são conflitantes em uma sociedade e, também, o equilíbrio entre eles, incluindo o papel da ideologia.
}

Assim, analisando que os PADOs se encontram neste âmbito de risco regulatório e possui relevância para a gestão orçamentária das empresas brasileiras de telecomunicação, fazse importante conhecer as principais características desse procedimento e suas implicações.

De acordo com Nascimento (2014), quando empresas reguladas pertencentes ao âmbito da ANATEL descumprem obrigações legais, contratuais ou regulamentares, estas ficam sujeitas a sanções que por sua vez são precedidas por um processo administrativo. Esses processos administrativos utilizados pela ANATEL são conhecidos como Procedimento para Apuração de Descumprimento de Obrigações (PADO). Alguns tipos de descumprimentos de obrigações que acarretam na instauração de PADOs pela ANATEL são:

- Comunicação multimídia (SCM) (ANATEL, 2001); 
- Interconexão (ITX) (ANATEL, 2005);

- Portabilidade (RGP) (ANATEL, 2007);

- Regulamento geral de qualidade (RGQ) (ANATEL, 2012a);

- Direitos e garantias dos usuários (DGU) (ANATEL, 2014). finalidade:

No art. 80 do Regimento Interno da agência (ANATEL, 2013), o PADO tem como

(...) averiguar o descumprimento de disposições estabelecidas em lei, regulamento, norma, contrato, ato, termo de autorização ou permissão, bem como em ato administrativo de efeitos concretos que envolva matéria de competência da Agência, e será instaurado de ofício ou a requerimento de terceiros, mediante reclamação ou denúncia.

De acordo com o mesmo artigo de referido dispositivo legal, o PADO é identificado por meio de código numérico composto por 15 dígitos. Por meio desse número de processo, todas as fases administrativas de um procedimento são concentradas, desde a demanda de físcalização até a efetiva aplicação da multa, quando confirmada a existência de conduta irregular. As fases do PADO, detalhadas no art. 80 do Regimento Interno da ANATEL (ANATEL, 2013), podem ser representadas conforme a Figura 1.

Figura 1 - Fases Regimentais do PADO

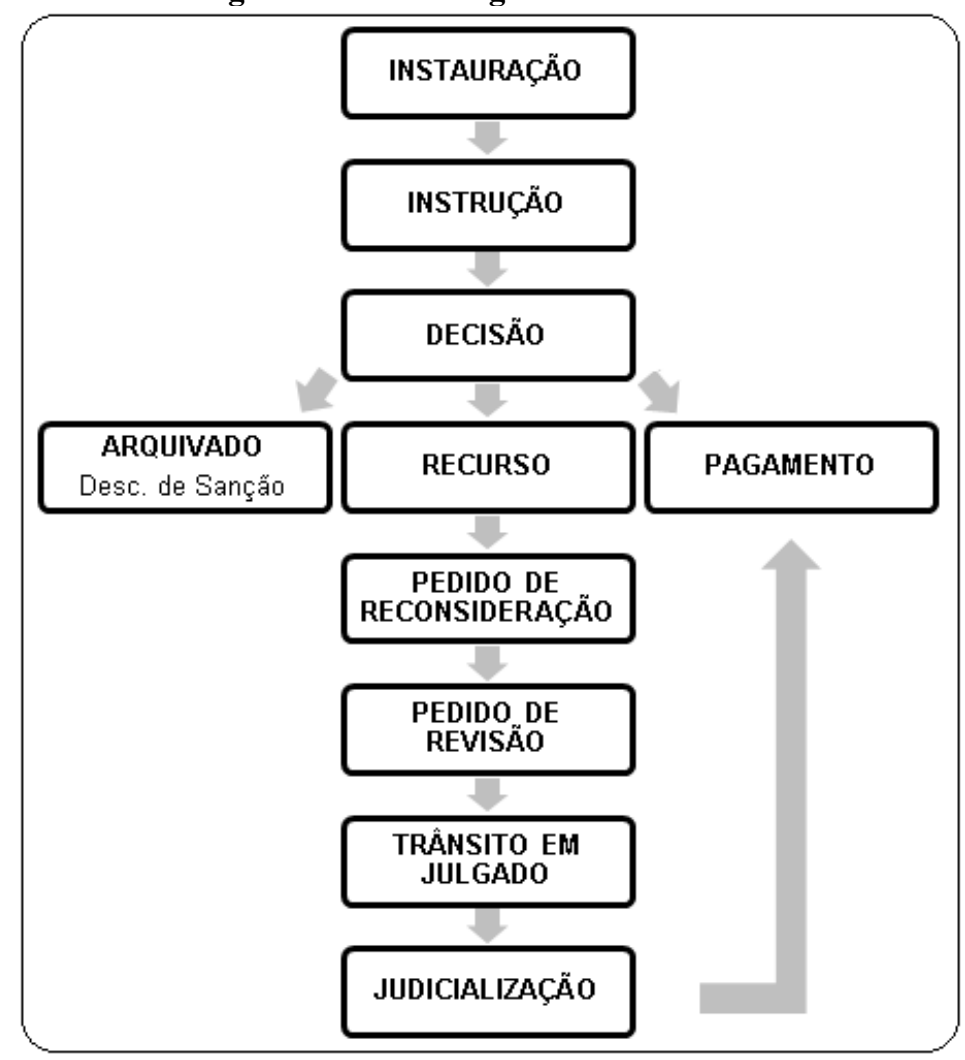

Fonte: Elaborado pelos autores, com base em ANATEL (2013)

Como pode ser observado pela Figura 1, o início do processo administrativo se dá pela instauração do mesmo, seguido da fase de instrução, onde se investiga e comprova os dados necessários à tomada de decisão quanto à aplicação da multa. Segundo o parágrafo único do art. 80 do Regimento Interno da Agência, “... se tratando de descumprimento de obrigações constatado em ação de fiscalização, o processo poderá iniciar-se com a emissão do Auto de Infração, que valerá como o Despacho Ordinatório de Instauração" (ANATEL, 2013). 
De acordo com o art. 82 do mesmo Regimento Interno, o réu terá quinze dias após a intimação para se defender e apresentar as provas que julgar cabíveis, sendo que o prazo para a conclusão da fase de instrução é de noventa dias contados a partir da intimação, podendo ser prorrogado pelo mesmo período diante da ocorrência de alguma situação que o justifique (ANATEL, 2013).

Após a fase de instauração, a superintendência responsável pela averiguação julgará se houve ou não o descumprimento e, por meio do sítio eletrônico da ANATEL, é divulgada a decisão, com consequente intimação ao interessado por despacho decisório devidamente fundamentado. A esse respeito, o art. 82, inciso V, do Regimento Interno comenta que, “... o prazo para a decisão final, após a completa instrução dos autos, é de 30 (trinta) dias, salvo prorrogação por igual período expressamente motivada" (ANATEL, 2013).

Se a ANATEL entender que não houve o descumprimento, o processo é arquivado por descaracterização de sanção. Caso contrário, a multa é aplicada, considerando que cabe recurso administrativo ou pedido de reconsideração da decisão da agência (ANATEL, 2013). Quanto à multa, seu pagamento deverá ser realizado dentro do prazo de 30 dias após a intimação da decisão definitiva (sujeita a desconto de $25 \%$ no caso de renúncia da empresa regulada em apresentar recurso de decisão em primeira instância), estando sujeita à correção monetária segundo a taxa Selic desde a data de intimação da cominação da multa até a decisão definitiva, em caso de pedido de reconsideração (ANATEL, 2012b).

O recurso ou pedido de reconsideração é a fase de rediscussão da decisão, o que é uma garantia do denunciado. O Regimento Interno em seu art. 115 observa que "O recurso administrativo será dirigido à autoridade que proferiu a decisão, e que decidirá sobre o seu conhecimento, e na hipótese de conhecimento, caso não se retrate, o encaminhará à autoridade hierarquicamente superior". No âmbito administrativo da ANATEL, a autoridade que profere a decisão é a Gerência ou a Superintendência, e a autoridade hierarquicamente superior é o Conselho Diretor. Portanto, quando o recurso é negado pela Gerência/Superintendência, o mesmo é enviado para o Conselho Diretor analisar. Caso determinado conselheiro não aceite o recurso, cabe a realização de um Pedido de Reconsideração devidamente fundamentado, que será distribuído a um conselheiro distinto daquele que negou o recurso (ANATEL, 2013).

Quando não existem mais recursos para alteração de uma decisão, ocorre a decisão da sentença definitiva (trânsito em julgado). Este momento é considerado o último "passo" processual, não havendo meio hábil para modificação da decisão após o recurso. A operacionalização do trânsito em julgado é realizada logo após o julgamento do recurso, com a publicação da decisão no Diário Oficial da União, conforme inciso IX, do art. 82, do Regimento Interno (ANATEL, 2013).

Portanto, considerando o exposto sobre a estrutura orçamentária e o processo em vigor de PADOs adotado pela ANATEL, entende-se que a mensuração e previsão destas contingências podem auxiliar a eficiência e eficácia do processo orçamentário das empresas de telecomunicação. Isto ocorrerá quando as organizações forem capazes de rastrear e antecipar o impacto dos PADOs em seu orçamento, tornando-o uma ferramenta de previsão correta e útil para a tomada de decisão.

\section{Metodologia}

Enquadrada como uma pesquisa descritiva quanto aos seus objetivos (CERVO; BERVIAN, 2002), adotou-se como estratégia de investigação a realização de um estudo de caso de cunho epistemológico positivista em uma empresa do setor de telecomunicações. Quanto às técnicas de coleta de dados, optou-se pela submissão de questionários junto a três funcionários de diferentes áreas envolvidas na gestão orçamentária dos PADOs. Com vistas à confirmação 
dos dados citados nos questionários, foi realizada uma análise de alguns documentos, obtidos junto à organização objeto do estudo, possibilitando, assim, a triangulação das informações. A coleta de dados foi realizada por meio de visita a campo, no período entre fevereiro e março de 2015.

A empresa objeto de estudo é do setor de telecomunicações, sujeita às normatizações e regulamentações da ANATEL, de origem brasileira, que atua na área de dados, voz e televisão. Em sua sede, local onde os procedimentos deste estudo foram realizados, ficam alocados diretores, gestores, especialistas e analistas das diversas áreas administrativas responsáveis pelas principais decisões e ações executadas na empresa. Quanto à representatividade do caso estudado, cita-se que, em 2014, a empresa analisada era apontada pela ANATEL como uma das quatro maiores empresas de telecomunicação do Brasil com base em sua participação de mercado, e também foi listada pela Fundação de Proteção e Defesa do Consumidor (PROCON) do Estado de São Paulo entre as 50 empresas com maior número de reclamações de usuários no mesmo ano.

Quanto aos funcionários para os quais o questionário foi aplicado, foram selecionados os seguintes cargos: (i) controller regulatório, responsável pela área regulatória, que faz a elaboração e o gerenciamento orçamentário dos PADOs; (ii) advogado especializado, lotado no departamento jurídico, responsável pelo acompanhamento e defesa dos PADOs nos âmbitos administrativo e judiciário e que também participa do processo de elaboração do orçamento, fornecendo informações necessárias sobre os processos à área regulatória; e (iii) analista de planejamento, pertencente à área de planejamento financeiro, que coordena o planejamento estratégico e o orçamento empresarial, consolidando as informações recebidas das diversas áreas da organização, o que inclui a área regulatória.

Ressalta-se que, para cada funcionário abordado, questões específicas foram elaboradas com a finalidade de coletar informações de acordo com suas atribuições na organização. As questões abertas que compuseram os questionários encontram-se no Apêndice deste artigo.

A respeito da análise documental, buscou-se analisar os PADOs instaurados contra a empresa objeto de estudo no período entre 2001 e 2014. Nesse levantamento, foram localizados 132 PADOs, com valor médio de R\$ 3 milhões. Nessa análise, procurou-se principalmente identificar as seguintes informações: processos por tipo, status de descumprimento, fase processual, risco de perda, situação de prescrição, montante envolvido, tempo de julgamento e tempo de pagamento. Com a coleta de documentos e recebimento das respostas aos questionários, os dados obtidos foram analisados, e estão apresentados a seguir.

\section{Análise dos Resultados}

Em um primeiro momento, foram analisados os 132 PADOs, partindo de sua classificação quanto ao seu tipo e seu status. Quanto ao status, considera-se a categorização realizada pela própria empresa, sendo considerado "em trâmite" aqueles que estão tramitando no âmbito administrativo da ANATEL, como "judicializado" aqueles que estão tramitando no judiciário, e como "arquivado" aqueles que já foram pagos ou descaracterizados de sanção. A Tabela 1 apresenta tais informações, de acordo com os documentos fornecidos pela empresa.

Ao analisar a Tabela 1, verifica-se que os temas mais frequentes de autuação no período analisado são Direitos e Garantias dos Usuários (DGU) e Indicadores de Qualidade (RGQ), representando $43 \%$ dos processos instaurados. Também se ressalta que cerca de $22 \%$ dos processos instaurados encontram-se vigentes em âmbito administrativo e cerca de $20 \%$ estão vigentes em âmbito judicial. Com o acesso a tais PADOs, verificou-se que, dos 55 processos vigentes, $44 \%$ estão prescritos, ou seja, não possuem mais valor administrativo, apesar de a ANATEL ainda considerá-los ativos. 
Márcia Maria dos Santos Bortolocci Espejo, Emanuelle Fabiana Said Branco, Henrique Portulhak e Patricia Villa Costa Vaz

Tabela 1 - PADOs por tipo e status de descumprimento, período 2001-2014

\begin{tabular}{l|l|c|c|c|c}
\hline Tipo & Descrição & Em trâmite & Judicializado & Arquivado & Total \\
\hline DGU & Direitos e Garantias do Usuário & 11 & 6 & 15 & $\mathbf{3 2}$ \\
\hline RGQ & Indicadores de Qualidade & 4 & 12 & 9 & $\mathbf{2 5}$ \\
\hline LE & Licenciamento de Estação & 6 & - & 16 & $\mathbf{2 2}$ \\
\hline Outros & Outros & - & 2 & 16 & $\mathbf{1 8}$ \\
\hline OF & Óbice à Fiscalização & 4 & 2 & 11 & $\mathbf{1 7}$ \\
\hline IS & Interrupção Sistêmica & 1 & 4 & 2 & $\mathbf{7}$ \\
\hline PORT & Portabilidade & - & - & 3 & $\mathbf{3}$ \\
\hline RN & Recurso de Numeração & 1 & - & 2 & $\mathbf{3}$ \\
\hline SCM & Serviço de Comunicação Multimídia & - & - & 3 & $\mathbf{3}$ \\
\hline ITX & Interconexão & 2 & - & - & $\mathbf{2}$ \\
\hline & & $\mathbf{2 9}$ & $\mathbf{2 6}$ & $\mathbf{7 7}$ & $\mathbf{1 3 2}$ \\
\hline
\end{tabular}

Fonte. Elaborado pelos autores, com base em documentos internos da empresa.

Os processos ativos para os quais ainda há algum risco de perda são classificados pelo advogado responsável lotado no departamento jurídico da empresa. De acordo com as respostas obtidas nos questionários, a classificação de risco de perda é realizada com base nas classificações presentes nas Deliberações 489/2005 e 594/2009 emitidas pela Comissão de Valores Mobiliários (CVM), em três categorias: (i) provável, quando a chance de o fato ocorrer é maior do que de o fato não ocorrer; (ii) remota, quando a chance de o fato ocorrer é considerada pequena; e (iii) possível, quando a chance de o fato ocorrer é menor que provável, mas maior que remota. A Tabela 2 apresenta os PADOs ativos de acordo com seu status e risco de perda.

Tabela 2 - PADOs por status e risco de perda, período 2001-2014

\begin{tabular}{l|c|c|c}
\hline Risco de Perda & Em trâmite & Judicializado & Total \\
\hline Possível & 24 & 17 & 41 \\
\hline Parcialmente Provável & - & 8 & 8 \\
\hline Provável & 5 & 1 & 6 \\
\hline Total Geral & $\mathbf{2 9}$ & $\mathbf{2 6}$ & $\mathbf{5 5}$ \\
\hline
\end{tabular}

Fonte. Elaborado pelos autores, com base em documentos internos da empresa.

De acordo com a Tabela 2, verifica-se que $74 \%$ dos PADOs ativos estão classificados como risco de perda possível, ou seja, existe para estes processos uma chance maior de que a empresa não sofra uma sanção do que de a sanção ocorrer. Deve-se ressaltar que, de acordo com informações obtidas nos questionários, o risco de cada PADO varia ao longo do tempo com base no resultado da análise da agência reguladora em cada fase. Com isso, um PADO classificado com risco de perda remoto em uma fase pode tornar-se provável na próxima fase dependendo do resultado da análise da agência. Também se observa que a empresa realiza uma adaptação com relação à sua referência de classificação de risco, ao verificar a categoria de risco "parcialmente provável".

Ainda conforme informações coletadas por meio de questionário, notou-se que o julgamento sobre o risco de cada processo é viabilizado pelo acesso permitido ao advogado especializado ao Sistema de Controle de Rastreamento de Documentos e Processos (SICAP), disponibilizado pela própria ANATEL. Por meio deste sistema, possibilita-se que o advogado autorizado tenha acesso ao sítio eletrônico da agência, consultando os autos processuais a qualquer tempo, seja por meio de cópias ou vistas dos mesmos. 
Ao analisar os dados de acordo com a fase do processo no qual cada PADO se encontra, tanto em âmbito administrativo quanto em âmbito judicial, resultou-se no exposto na Tabela 3 .

Tabela 3 - PADOs por status e fase, período 2001-2014

\begin{tabular}{l|c|c|c}
\hline Fase & Em trâmite & Judicializado & Total \\
\hline Instrução & 17 & - & $\mathbf{1 7}$ \\
\hline Recurso & 10 & 2 & $\mathbf{1 2}$ \\
\hline Pedido de Reconsideração & 2 & 2 & $\mathbf{4}$ \\
\hline Pedido de Revisão & - & 4 & $\mathbf{4}$ \\
\hline Trânsito em Julgado & - & 18 & $\mathbf{1 8}$ \\
\hline Total & $\mathbf{2 9}$ & $\mathbf{2 6}$ & $\mathbf{5 5}$ \\
\hline
\end{tabular}

Fonte. Elaborado pelos autores, com base em documentos internos da empresa.

A Tabela 3 indica que $31 \%$ dos PADOS ainda não foram julgados, ou seja, estão na fase de instrução e não têm multa aplicada. Os demais processos já foram apenados e estão em processo de defesa, tramitando no âmbito administrativo da ANATEL ou no âmbito judicial, de acordo com as suas fases. Esclarece-se que o "trânsito em julgado" não é uma fase de processo, mas sim a decisão da sentença em definitiva, não cabendo mais recurso sobre ela, ou seja, após o trânsito em julgado, a única opção da empresa é judicializar o processo caso a mesma não queira optar pelo pagamento do PADO. Também se ressalta que praticamente $50 \%$ dos PADOs ativos foram instaurados há mais de oito anos, sendo que alguns deles ainda estão na fase de instrução, ou seja, sem julgamento.

De acordo com informações transmitidas pelos funcionários questionados, a judicialização de um PADO pode ocorrer a qualquer momento. Contudo, a judicialização é mais comum após o trânsito em julgado. Os critérios utilizados pela empresa para judicializar um PADO são concentrados em três fatores: (i) quando comprovada a ilegalidade ou desproporcionalidade da sanção aplicada; (ii) quando da existência de subsídios suficientes que comprovem a ilegalidade ou desproporcionalidade da sanção aplicada; ou (iii) quando há justificativa financeira para judicialização, ou seja, quando o valor da sanção discutida foi calculado individualmente e não à luz do precedente aberto, que seria o correto.

Quanto às provisões, a empresa estudada toma com base o risco de perda avaliado pelo departamento jurídico, que leva em consideração o tipo de descumprimento de obrigação, o status, a prescrição e as fases. Dos 55 PADOs ativos, 16 foram considerados para provisão, conforme detalhado pela Tabela 4.

Considerando os dados presentes na Tabela 4, observa-se que 44\% dos PADOs provisionados concentram-se na fase de recurso, $94 \%$ não estão prescritos e $50 \%$ têm risco de perda parcialmente provável. Acrescenta-se que, do valor total representado nos procedimentos, $37 \%$ desse montante foi considerado para provisão.

De acordo com as informações coletadas por meio do questionário, um fator que facilita a realização dos cálculos dos valores a serem provisionados e, por consequência, considerados no planejamento orçamentário, é o acesso ao Sistema Boleto, ferramenta elaborada pela ANATEL e disponível em seu sítio eletrônico, que permite consultas os débitos atualizados, gerar boletos e imprimir comprovantes de pagamentos. Este acesso a um sistema informatizado pode auxiliar na elaboração das provisões de contingentes, aproximando os valores estimados dos reais e tornando o orçamento uma ferramenta com informações mais verídicas e úteis para a tomada de decisão (FANK; ANGONESE; LAVARDA, 2011). 
Márcia Maria dos Santos Bortolocci Espejo, Emanuelle Fabiana Said Branco, Henrique Portulhak e Patricia Villa Costa Vaz

Tabela 4 - PADOs provisionados, período 2001-2014

\begin{tabular}{|c|c|c|c|c|c|c|c|}
\hline $\mathbf{N}^{\mathbf{0}}$ & Ano & Tipo & Status & Fase & Risco de Perda & Prescrito & \% Provisão \\
\hline 1 & 2004 & RGQ & Judicializado & P. Reconsideração & Parc. Provável & Não & $64 \%$ \\
\hline 2 & 2004 & OUTROS & Judicializado & Trans. Julgado & Possível & Sim & $100 \%$ \\
\hline 3 & 2004 & DGU & Judicializado & Trans. Julgado & Provável & Não & $100 \%$ \\
\hline 4 & 2005 & IS & Judicializado & P. de Revisão & Parc. Provável & Não & $50 \%$ \\
\hline 5 & 2005 & IS & Judicializado & P. de Revisão & Parc. Provável & Não & $50 \%$ \\
\hline 6 & 2005 & IS & Judicializado & P. de Revisão & Parc. Provável & Não & $100 \%$ \\
\hline 7 & 2005 & IS & Judicializado & P. de Revisão & Parc. Provável & Não & $87 \%$ \\
\hline 8 & 2006 & RGQ & Judicializado & Trans. Julgado & Parc. Provável & Não & $58 \%$ \\
\hline 9 & 2009 & RGQ & Judicializado & P. Reconsideração & Parc. Provável & Não & $60 \%$ \\
\hline 10 & 2010 & $\mathrm{OF}$ & Em trâmite & Recurso & Provável & Não & $100 \%$ \\
\hline 11 & 2010 & DGU & Em trâmite & Recurso & Provável & Não & $100 \%$ \\
\hline 12 & 2011 & OF & Em trâmite & Recurso & Possível & Não & $100 \%$ \\
\hline 13 & 2011 & LE & Em trâmite & Recurso & Provável & Não & $100 \%$ \\
\hline 14 & 2011 & $\mathrm{LE}$ & Em trâmite & Recurso & Provável & Não & $100 \%$ \\
\hline 15 & 2011 & $\mathrm{LE}$ & Em trâmite & Recurso & Provável & Não & $100 \%$ \\
\hline 16 & 2011 & RGQ & Judicializado & Recurso & Parc. Provável & Não & $75 \%$ \\
\hline
\end{tabular}

Nota. Fonte. Elaborado pelos autores, com base em documentos internos da empresa.

Informações sobre tempo médio de pagamento e de julgamento também foram extraídas dos documentos analisados. Verificou-se que, dos 132 PADOs instaurados no período analisado, 115 foram julgados, sendo que a média de tempo de julgamento é de 2,9 anos. Sobre o pagamento, que de acordo com informações dos funcionários questionados ocorre por opção (com desconto de $25 \%$, quando a empresa reconhece a existência da infração e a razoabilidade da multa aplicada ou quando a empresa não possui subsídios para comprovar a regularidade da conduta) ou por obrigação (quando ocorre a decisão definitiva), notou-se que 40 processos foram arquivados pelo pagamento no período analisado, com tempo médio de pagamento de 3,6 anos a partir do momento de instauração.

No contexto apresentado, foram questionados aos funcionários da empresa objeto de estudo sobre os principais fatores que são considerados para a elaboração do orçamento dos PADOs. Com base nas respostas obtidas, podem ser destacados os seguintes fatores como elementos principais de subsídio para elaboração do orçamento:

- Pagamento com desconto: ao renunciar o direito de recorrer da decisão, a empresa tem o prazo de trinta dias contados a partir do julgamento para realizar o pagamento do PADO e obter o desconto de $25 \%$;

- Provisão: a provisão é realizada com base na análise de risco de perda feito pelo departamento jurídico e nas características dos PADOs, como o tipo de descumprimento de obrigação, o status, a prescrição e as fases;

- Premissa empresarial: a variação do orçamento definida pelo Planejamento Financeiro é um dos limitantes na decisão da aprovação do orçamento. O processo de aprovação é revisado pelo gestor da área e levado para reunião de aprovação com o Diretor e o VicePresidente da área. Nesta reunião, são expostas as premissas e feita a defesa do valor obtido. Eventualmente são solicitados ajustes para que o valor orçado fique aderente às premissas empresarias definidas pelo Planejamento Financeiro. Após esta aprovação, uma segunda aprovação é necessária pelo CFO e CEO da empresa.

Todavia, dificuldades foram relatadas pelos funcionários questionados para que seja possível realizar a provisão dos valores de cada processo, o que compromete a gestão orçamentária da empresa. Foram citados como principais fatores: (i) a falta de um padrão de metodologia da ANATEL para calcular as multas, e (ii) a falta de um padrão de calendarização 
para julgar o mérito em cada fase do processo. Estes dois itens ressaltam o exposto por Frezatti et al. (2010), ao indicarem que o grau de realidade das metas e processos é fundamental para o adequado andamento do sistema orçamentário. Isto significa que, sem uma possibilidade de previsão correta, a veracidade das informações do orçamento resta prejudicada, afetando sua execução e acompanhamento.

De acordo com as informações coletadas, tais circunstâncias acabam resultando nas seguintes situações:

a. Multas milionárias e desproporcionais: identificou-se que os PADOs com um mesmo tipo de infração foram julgados de formas distintas, resultado da utilização de diferentes metodologias julgadas pelas diversas áreas técnicas da ANATEL responsáveis pelo processo de apuração e punição;

b. Falta de um histórico consistente: por meio da análise dos dados, observou-se a dificuldade em utilizar a base de dados como premissa para elaborar o orçamento dos PADOs, pois a falta de um padrão de metodologia pela ANATEL gera constante inconsistência das informações contempladas nos orçamentos;

c. Prescrição dos PADOs: verificou-se que 44\% dos PADOs em trâmite e judicializados estão prescritos e, em tese, não teriam mais valor administrativo. Entretanto, como não há um prazo máximo definido pela ANATEL para julgar o mérito em cada fase do PADO, a agência ainda os considera ativos, o que traz incertezas à empresa em seu processo de planejamento orçamentário;

d. Baixa arrecadação: constatou-se que a falta de um processo estruturado que garanta que as irregularidades detectadas sejam julgadas adequadamente gera subsídios para a empresa optar pelo não pagamento da multa e recorrer da decisão;

e. Oscilação do risco de perda: pelos critérios da empresa, a classificação do risco do PADO varia no tempo de acordo com o resultado da análise da ANATEL em cada fase. Como o planejamento orçamentário é realizado com base no risco, este por sua vez fica totalmente suscetível ao julgamento da Agência, o que não possui prazo definido e, por conta dos fatores mencionados, causa instabilidade no processo de planejamento e controle orçamentário da empresa.

Diante destes achados, analisa-se que o planejamento e controle orçamentário das empresas de telecomunicação precisam considerar os aspectos legais do PADO em sua elaboração. Isto porque estes procedimentos de descumprimento acabam tornando-se parte relevante do orçamento, consumindo recursos tanto financeiros quanto pessoais, em todo seu processo. Portanto, o processo orçamentário não pode estar alheio às características contingenciais do setor ao qual a organização pertence, sob pena de tornar as informações orçamentárias vazias de significados e prejudiciais para a tomada de decisão.

\section{Considerações Finais}

A pesquisa em questão buscou investigar o tratamento dos PADOS na gestão orçamentária de uma empresa de telecomunicações. Para isso, procurou-se compreender os critérios e posicionamentos adotados pela organização objeto de estudo de caso na gestão orçamentária desses procedimentos.

A partir do referencial teórico e do estudo de caso detalhado, foi possível verificar que o controle e planejamento dos PADOs é realizado pelos analistas, gestores e diretores da empresa investigada de uma forma adequada, proporcional à importância e à severidade dessas situações. Entretanto, percebeu-se que o planejamento orçamentário é prejudicado pela falta de uma metodologia padrão da agência reguladora que, estando adequada às necessidades de 
gestão orçamentária das empresas reguladas, possibilitaria a estimação de parâmetros importantes para a elaboração do orçamento pela empresa estudada.

Observou-se, também, que a falta de um padrão de calendarização afeta diretamente a previsibilidade do pagamento e da provisão, pois não há um prazo máximo definido pela ANATEL para julgar o mérito em cada fase do PADO, com isso, não existe um histórico consistente que possa ser levado em consideração na estimativa de quando o PADO deve ser pago ou provisionado. Tal fato comprova-se pela quantidade expressiva de PADOs prescritos, que teoricamente não teriam mais valor administrativo e, no entanto, permanecem ativos na visão da ANATEL; alguns deles instaurados há mais de 10 anos e ainda em fase de instrução, sem julgamento.

Outro fator que afeta o orçamento é a classificação do risco de perda, pois varia no tempo de acordo com o resultado da análise da ANATEL em cada fase, prejudicando o planejamento da provisão, que é feito com base na classificação do risco, das fases e da prescrição. Com isso, os 41 PADOs classificados com o risco de perda possível podem a qualquer momento ser analisados pela ANATEL e terem sua classificação alterada, ficando, consequentemente, descobertos de orçamento, já que não foram provisionados.

Por fim, a falta de um padrão de metodologia para estimar o cálculo das multas até 26 de agosto de 2014 deixa a empresa vulnerável para elaborar o orçamento dos PADOs não julgados, ficando o valor definido totalmente sujeito a interpretações da ANATEL. Mesmo com a nova metodologia, nota-se que ainda não ficou claro para a empresa alguns critérios considerados no cálculo da multa, o que compromete a previsão do orçamento dos 17 PADOs que ainda não foram julgados.

Diante do resultado da análise dos PADOs, percebeu-se que a ANATEL não possui um processo estruturado de modo a garantir que as irregularidades detectadas na fiscalização sejam julgadas tempestivamente. Além disso, identificou-se, pela quantidade expressiva de multas milionárias e desproporcionais, que a falta de metodologia no processo dificulta o planejamento orçamentário da empresa, podendo comprometer a execução de seu planejamento estratégico e o alcance dos resultados almejados.

Contudo, verifica-se que, para a empresa alcançar os seus objetivos estratégicos, se faz necessário uma correta decisão antecipada de suas ações, pois, mesmo diante de um cenário de dificuldades, existem elementos que podem contribuir para se ter um planejamento, controle e orçamento capazes de integrar todo o processo e gerenciar cenários futuros de forma eficiente. Diante disso, sugere-se que a empresa busque fazer um histórico do tempo médio de julgamento por tipo de PADO e de pagamento por ano de instauração, avaliando possíveis alterações e padrões, buscando definir uma previsibilidade na elaboração do planejamento. Sugere-se, também, que a empresa acompanhe as ações da agência reguladora com as outras empresas do mesmo ramo, procurando identificar similaridades no julgamento e cálculo dos PADOs.

Portanto, diante das evidências encontradas, analisa-se que as empresas do setor de telecomunicações têm seu orçamento fortemente impactado pelas decisões e procedimentos implantados pela sua agência reguladora. A dificuldade da previsão de contingências como o PADO pode prejudicar a eficiência do setor, que se vê diante de contingências difíceis de serem provisionadas, dado a impossibilidade de se compreender as metodologias de cálculo das multas, ou mesmo do prazo de julgamento e prescrição das ações.

Além disso, algumas sugestões para futuras pesquisas podem ser consideradas. Recomenda-se, em primeiro lugar, que sejam realizadas futuras investigações a partir da nova metodologia adotada pela ANATEL em 26 de agosto de 2014. Dentre as principais alterações ocorridas por meio das portarias emitidas nessa data e que possam ter reflexões na gestão orçamentária das empresas de telecomunicação, destaca-se a maior especificação para o cálculo das multas, por meio de quadros e fórmulas, conforme a classificação das sanções 
administrativas em categorias (leve, média, grave), que por sua vez são definidas pelo período de análise, dimensão de público e parcela de usuários prejudicada (ISTOÉ DINHEIRO, 2014). Dessa forma, a realização de investigações comparativas pode identificar com detalhes se houve melhorias no processo de julgamento dos PADOs instaurados desde então, e quais os reflexos dos processos afetados pela nova metodologia na gestão orçamentária das empresas de telecomunicações.

Adicionalmente, sugere-se a realização de estudos de caso em entidades semelhantes, de forma a confirmar se as mesmas dificuldades são encontradas em seus processos de planejamento orçamentário, se tais dificuldades ainda ocorrem apesar das alterações no marco regulatório, e verificar quais os procedimentos que possam servir de benchmark para entidades semelhantes.

\section{Referências}

ANATEL - Agência Nacional de Telecomunicações. Resolução no 272 , de 9 de agosto de 2001. Aprova o Regulamento do Serviço de Comunicação Multimídia. Disponível em $<$ http://www.anatel.gov.br/legislacao/resolucoes/16-2001/5-resolucao-272>. Acesso em 17 fev. 2016.

ANATEL - Agência Nacional de Telecomunicações Resolução n ${ }^{0}$ 410, de 11 de julho de 2005. Aprova o regulamento geral de interconexão. Disponível em $<$ http://www.anatel.gov.br/legislacao/resolucoes/2005/167-resolucao-410>. Acesso em 17 fev. 2016.

ANATEL - Agência Nacional de Telecomunicações. Resolução n 460, de 19 de março de 2007. Aprova o Regulamento Geral de Portabilidade - RGP. Disponível em $<$ http://www.anatel.gov.br/legislacao/resolucoes/22-2007/8-resolucao-460>. Acesso em 17 fev. 2016.

ANATEL - Agência Nacional de Telecomunicações. Resolução n⿳ 605, de 26 de dezembro de 2012. Aprova o Regulamento de Gestão de Qualidade da Prestação do Serviço Telefônico Fixo Comutado - RGQ-STFC. Disponível em

$<$ http://www.anatel.gov.br/legislacao/resolucoes/2012/440-resolucao-605>. Acesso em 17 fev. 2016.

ANATEL - Agência Nacional de Telecomunicações. Resolução $\mathbf{n}^{\mathbf{0}}$ 589, de 7 de maio de 2012. Aprova o Regulamento de Aplicação de Sanções Administrativas. Disponível em $<$ http://www.anatel.gov.br/legislacao/resolucoes/2012/191-resolucao-589>. Acesso em 17 fev. 2016.

ANATEL - Agência Nacional de Telecomunicações. Resolução no 612, de 29 de abril de 2013. Aprova o Regimento Interno da ANATEL. Disponível em $<$ http://www.anatel.gov.br/legislacao/resolucoes/2013/450-resolucao-612>. Acesso em 17 fev. 2016.

ANATEL - Agência Nacional de Telecomunicações. Resolução no 632, de 7 de março de 2014. Aprova o Regulamento Geral de Direitos do Consumidor de Serviços de Telecomunicações - RGC. Disponível em $<$ http://www.anatel.gov.br/legislacao/resolucoes/2014/750-resolucao-632>. Acesso em 17 fev. 2016. 
CAMACHO, Fernando; BRAGANÇA, Gabriel; ROCHA, Katia. A remuneração de capital nas telecomunicações e o novo contexto regulatório brasileiro. BNDES Setorial, n. 22, p. 89-110, 2005.

CERVO, Amado Luiz; BERVIAN, Pedro Alcino. Metodologia científica. 5. ed. São Paulo: Prentice-Hall, 2002.

COASE, Ronald H. The Nature of the Firm. Economic NS, v. 5, p. 386-405, 1937

COVALESKI, Mark. et al. Budgeting research: three theoretical perspectives and criteria for selective integration. In: CHAPMAN, Christopher S.; HOPWOOD, Anthony G.; SHIELDS, Michael D. (Org.). Handbook of Management Accounting Research. Amsterdam: Elsevier, 2007. v. 2, p. 587-624. http://dx.doi.org/10.1016/S1751-3243(06)02006-2

FANK, Odir Luis; ANGONESE, Rodrigo; LAVARDA, Carlos Eduardo Facin. A percepção dos gestores acadêmicos de uma IES quanto às críticas ao orçamento. Contabilidade, Gestão e Governança, v. 14, n. 1, p. 82-93, 2011.

FREZATTI, Fábio. Orçamento empresarial: planejamento e controle gerencial. $5^{\mathrm{a}}$. ed. São Paulo: Atlas, 2009.

FREZATTI, Fábio et al. Críticas ao orçamento: problemas com o artefato ou a não utilização de uma abordagem abrangente de análise? ASAA - Advances in Scientific and Applied Accounting, v. 3, n. 2, p. 190-216, 2010. http://dx.doi.org/10.14392/ASAA.2010030203

GALINA, Simone Vasconcelos Ribeiro; PLONSKI, Guilherme Ary. Inovação no setor de telecomunicações no Brasil: uma análise do comportamento empresarial. Revista Brasileira de Inovação, v. 4, n. 1, p. 129-155, 2009.

GUERREIRO, Reinaldo. Um modelo de sistema de informação contábil para mensuração do desempenho econômico das atividades empresariais. Caderno de Estudos FIPECAFI, n. 4, p. 1-19, 1992. http://dx.doi.org/10.1590/S1413-92511992000100002

HANSEN, Stephen C.; OTLEY, David T.; VAN DER STEDE, Wim A. Practice developments in budgeting: an overview and research perspective. Journal of Management Accounting Research, v. 15, n. 1, p. 95-116, 2003.

HARTMANN, Frank G. H.; MAAS, Victor S. Why business unit controllers create budget slack: involvement in management, social pressure, and machiavellianism. Behavioral Research in Accounting, v. 22, n. 2, p. 27-49, 2010. http://dx.doi.org/10.2308/bria.2010.22.2.27

HORNGREN, Charles T.; SUNDEM, Gary L.; STRATTON, William O. Contabilidade gerencial. 12. ed. São Paulo: Pearson, 2004.

ISTOÉ DINHEIRO. ANATEL define cálculo de multas em telecomunicações. Economia. 03 set. 2014. Disponível em:

$<$ http://www.istoedinheiro.com.br/noticias/economia/20140903/ANATEL-define-calculomultas-telecomunicacoes/186321>. Acesso em 13 mar. 2017.

KUBOTA, Luis Claudio. Risco regulatório em telecomunicações: análise da polêmica sobre o reajuste das tarifas pelo IGP-DI. Texto para discussão, Brasília, Instituto de Pesquisa Econômica Aplicada (IPEA), no 1065, ISSN 1415-4765, janeiro, 2005.

KUPFER, David; HASENCLEVER, Lia. Economia Industrial: Fundamentos teóricos e práticas no Brasil. Rio de Janeiro: Campus, 2002. Cap. 12. 
LUNKES, Rogério João. Contribuição à melhoria do processo orçamentário empresarial. Tese (Doutorado em Engenharia da Produção) - Universidade Federal de Santa Catariana, Florianópolis, 2003.

LUNKES, Rogério João. Manual de orçamento. 2. ed. São Paulo: Atlas, 2007.

NASCIMENTO, Marina Georgia de Oliveira. O procedimento de apuração de descumprimento de obrigações no âmbito da ANATEL. Revista Jus Navigandi, 19, 4046, 2014. Disponível em: <https://jus.com.br/artigos/29096>. Acesso em 14 fev. 2016.

OYADOMARI, José Carlos et al. Fatores que influenciam a adoção de artefatos de controle gerencial nas empresas brasileiras: um estudo exploratório sob a ótica da teoria institucional. Revista de Contabilidade e Organizações, v. 2, n. 2, p. 55-70, 2008. http://dx.doi.org/10.11606/rco.v2i2.34705

SALGADO, Lucia Helena. Agências regulatórias na experiência brasileira: um panorama do atual desenho institucional. Texto para discussão, Rio de Janeiro, Instituto de Pesquisa Econômica Aplicada (IPEA), n. 941, ISSN 1415-4765, março, 2003.

SCHNORRENBERGER, Darci. et al. Utilidade percebida do planejamento orçamentário: estudo comparativo nas empresas do setor de comércio varejista de materiais de construção e de transporte coletivo. Revista Administração em Diálogo, v. 15, n. 2, p. 79-102, 2013. http://dx.doi.org/10.20946/rad.v15i2.12725

TELECO. Investimentos Brasil. 2016. Disponível em

$<$ http://www.teleco.com.br/estatis.asp>. Acesso em 16 fev. 2016.

ZIMMERMAN, Jerold L. Accounting for decision making and control. 7th ed. New York: McGraw-Hill, 2011.

ZYLBERSTAJN, Decio. Estruturas de governança e coordenação do agribusiness: uma aplicação da nova economia das instituições. São Paulo, 1995. Tese (Livre Docência) Faculdade de Economia e Administração da Universidade de São Paulo. Cap. 1. 
Apêndice - Questionário aplicado às pessoas envolvidas no processo

Controller regulatório:

1) Quais são as premissas utilizadas para a elaboração do orçamento de PADOs?

2) Quais são as dificuldades na elaboração do orçamento do PADOs?

3) Como é o processo de aprovação do orçamento do PADOs?

Advogado especializado:

1) Quais os critérios utilizados pela empresa para classificar os PADOs quanto ao seu tipo?

2) Quais são os critérios utilizados pela empresa para classificar os PADOs quanto ao risco?

3) Quais referências bibliográficas são utilizadas para descrever os riscos de perda dos PADOs?

4) Quais referências bibliográficas são utilizadas para descrever a teoria da prescrição e quais os tipos?

5) Quais são os critérios utilizados pela empresa para classificar os PADOs como prescritos?

6) Quais são os critérios utilizados para provisionar os PADOs?

7) Quais são os critérios utilizados para optar pelo pagamento do PADO sem recorrer e obter o desconto oferecido pela ANATEL?

8) Que evento marca a decisão pela obrigação do pagamento do PADO?

9) Quais são os critérios utilizados para judicializar um PADO?

10) Qual sistema da ANATEL é utilizado para acompanhar os PADOs?

11) Qual sistema e quais critérios a ANATEL adota para acompanhar a atualização monetária de débito dos PADOs?

Analista de planejamento:

1) Quais as premissas utilizadas pela empresa para aprovar o orçamento dos PADOs?

2) Existe algum processo para revisão periódica do orçamento pela sua empresa? Caso sim, por favor descreva. 